\title{
Low Renin Hypertension - Is It a Stage of Essential Hypertension?
}

\author{
Keishi Abe, Nobuo Irokawa, Haruki Aoyagi, Masahide \\ Seino, Minoru Yasujima, Kancho Ritz, Toru Ito, Satoru \\ Chiba, Yutaka Sakurat, Keitaro Saito, T'akashi Kugaka, \\ Yoichi Otsuka, Seizi Miyazaki and Kaoru Yoshinaga \\ Second Department of Internal Medicine, Tohoku University \\ School of Medicine, Sendai
}

Abe, K., Irokawa, N., Aoyagi, H., Serno, M., Yasujima, M., Ritz, K., Ito, T., Chiba, S., Sakurat, Y., Satro, K., Kusaka, T., Otsuka, Y., Miyazaki, S. and Yoshinaga, K. Low Renin Hypertension-Is It a Stage of Essential Hypertension ? Tohoku J. exp. Med., 1977, 121 (4), 347-354-Resting plasma renin activity (PRA) and PRA after the load of furosemide i.v. and two-hour's upright posture were studied on 139 healthy normotensive subjects and 200 patients with essential hypertension. Regarding the age factor, the estimated values in control subjects were very low in the advanced ages over 60 years, while no significant differences were found in the subjects aged from 20 to 59 years. In essential hypertension, a similar relationship between renin and aging was observed. The patients with essential hypertension were classified into 3 groups according to the resting PRA values; low, normal and high. There were no significant differences among the 3 groups concerning the mean ages and the blood pressure. Regarding the incidence of low PRA hypertension at different ages there were no significant differences among the decades under 60 years of age. On the other hand, all hypertensive patients were classified into 3 groups according to their responses of renin secretion; low responders, normal responders, and high responders. There was a positive correlation between the incidences of hyporesponders of renin secretion and the age. Higher incidences of hyporesponders were obtained in older patients. The incidence of hyperresponders was higher in younger patients than in older patients. Our study revealed that the incidences of low resting PRA were similar in each decade under 60 years, and it seems unlikely that low renin hypertension is a stage in a long-term course of essential hypertension. On the contrary, the hyporesponders of renin secretion to the load are apparently related to the age. It is concluded that low PRA essential hypertension must be distinct from the hyporesponder of renin secretion. _ _ - low renin essential hypertension; renin subgroup; hyporesponder; age factor

It has been generally accepted that 20 to $30 \%$ of patients with essential hypertension have low plasma renin activity (PRA) and fail to respond to the stimulation of sodium restriction and standing (Brunner et al. 1972: Crane et al. 1972). Low PRA essential hypertension differs from primary aldosteronism,

Received for publication, November 5, 1976.

This work was supported by grants (No. 157229 and No. 110810) from the Ministry of Education of Japan and grants for Specific. Diseases (Juvenile Malignant Hypertension and Chronic Renal Failure) from the Ministry of Health and Welfare of Japan. 
because the patients of this group have normal or low aldosterone secretion rates (Ledingham et al. 1967), However, the fact that a mineralocorticoid inhibitor spironolactone or an inhibitor of adrenal steroidogenesis aminogluthetimide lowers blood pressure in patients with suppressed PRA suggests that mineralocorticoid excess may somehow be involved in the mechanism of suppressed renin secretion (Woods et al. 1969). Several hormones with mineralocroticoid activity have been incriminated in the pathognesis of low PRA essential hypertension by many researchers (Melby et al. 1971; Sennett et al. 1975). But there is little evidence of the involvement of these substances.

Recently, Padfield et al. (1975) reported that low PRA hypertension is a stage in the course of essential hypertension, because PRA falls with the duration of this disease. To elucidate the problem whether low PRA essential hypertension is a result of the long-term effects of high blood pressure on the kidney or not, the relationship between renin, hypertension, and its duration was studied. Padfield's hypothesis was not supported. We report our results below.

\section{Patients and Methods}

One hundred thrity-nine healthy normotensive subjects and 200 patients with essential hypertension were studied. The normotensive individuals ranged in age from 11 to 81 years. Fifty-seven were men and 82 were women. Hypertensive patients ranged in age from 11 to 71 years. One hundred thirtymeight were men and 62 were women. The diagnosis of essential hypertension was established by history, physical examination, routine laboratory tests, intravenous pyelography, renal arteriography and determinations of plasma 11-OHCS, aldosterone, and urinary catecholamines or vanillyl mandelic acid. Renal arteriography was done whenever the patients had abnormal findings in intravenous pyelography and PRA values.

Antihypertensive drugs were discontinued at least two weeks before the study, and sodium intake (approximately 250 mmoles per day) was allowed for at least one week before PRA determination. Sampling of blood was done with fasting patients kept in recumbent position for one hr in the morning. To evaluate the reaction of renin secretion to the load, sampling of blood was done after intravenous injection of furosemide (1 $\mathrm{mg} / \mathrm{kg}$ ) and taking two-hour's upright posture. PRA in peripheral blood was determined by a sensitive method of angiotensin I radioimmunoassay (Abe et al. 1972).

One milliliter of plasma was incubated at $37^{\circ} \mathrm{C}$ at $\mathrm{pH} 5.5$ for $6 \mathrm{hr}$ with disodium ethylene diamine tetraacetic acid (EDTA) and disopropyl fluorophosphate (DFP). The sample was then diluted tenfold with physiologic saline, and heated in boiling water bath for $5 \mathrm{~min}$. After centrifugation, angiotensin $I$ in the supernatant was assayed radioimmunologically. This method was approximately 4 times more sensitive than Haber's method. The PRA values determined by the present method showed a good correlation with those of bioassay.

\section{Results}

Renin and age

The estimated values of resting peripheral vein PRA ranged from 2 to 36 $\mathrm{ng} / \mathrm{ml}$ with a mean of $12.4 \mathrm{ng} / \mathrm{ml}$ (s.E. 0.62 ) in 139 control subjects and from less than 2 to $100 \mathrm{ng} / \mathrm{ml}$ with a mean of $15.6 \mathrm{ng} / \mathrm{ml}$ (S.E. 1.3) in 200 patients with essential hypertension. Fig. 1 shows the PRA levels at different ages in healthy 


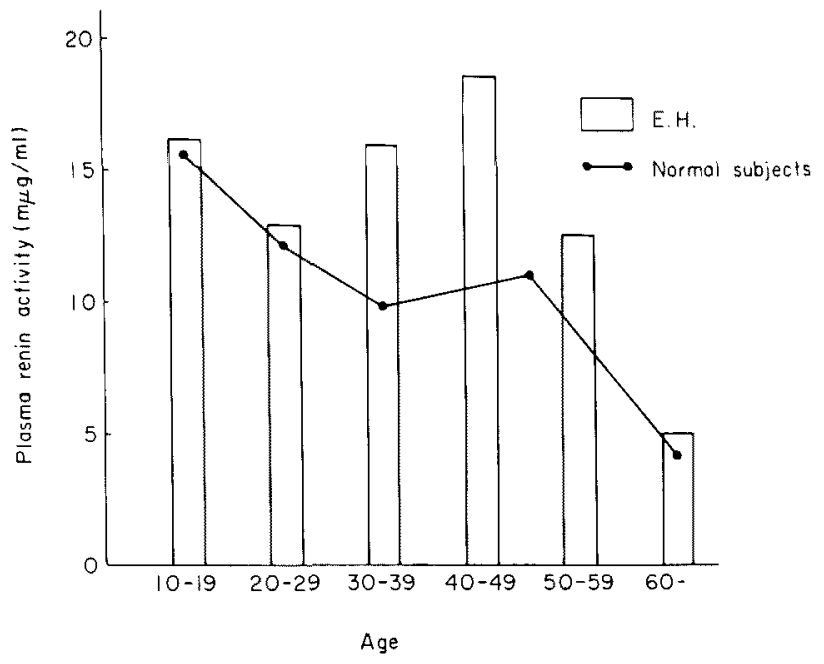

Fig. 1. The resting PRA levels at different ages in 139 healthy persons and 200 hypertensive patients.

persons and hypertensive patients. In healthy subjects, the mean PRA value of 42 persons aged under 19 years was $15.4 \mathrm{ng} / \mathrm{ml}$ (s.E. 1.1), 48 persons aged 20 to 29 years $12.2 \mathrm{ng} / \mathrm{ml}$ (s.e. 0.9), 20 persons aged 30 to 39 years $9.7 \mathrm{ng} / \mathrm{ml}$ (s.E. 1.1 ), 13 persons aged 40 to 59 years $11.0 \mathrm{ng} / \mathrm{ml}$ (s.E. 2.6), and 16 persons aged over 60 years $4.1 \mathrm{ng} / \mathrm{ml}$ (s.e. 0.6), respectively. The PRA level in younger subjects aged under 19 years was slightly higher than those in other age groups. On the contrary, the estimated values were very low in the advanced ages over 60 years. In the subjects aged from 20 to 59 years, however, no significant differences in the PRA levels were found $(p>0.05)$.

In essential hypertension, similar relationship between renin and aging was observed. The mean PRA value of 20 cases aged under 19 years was $16.1 \mathrm{ng} / \mathrm{ml}$ (s.e. 3.3 ), 40 cases aged 20 to 29 years $12.9 \mathrm{ng} / \mathrm{ml}$ (s.E. 2.0 ), 56 cases aged 30 to 39 years $15.9 \mathrm{ng} / \mathrm{ml}$ (s.E. 2.7), 51 cases aged 40 to 49 years $18.6 \mathrm{ng} / \mathrm{ml}$ (s.E. 3.1 ), 24 cases aged 50 to 59 years $12.5 \mathrm{ng} / \mathrm{ml}$ (s.e. 2.2), and 5 cases aged over 60 years 4.9 $\mathrm{ng} / \mathrm{ml}$ (s.e. 1.8), respectively.

As revealed in control subjects, the PRA level in older patients aged over 60 years was prominently low. In the patients aged under 59 years, however, no significant differences between renin and aging were found $(p>0.05)$.

\section{Frequency distribution}

The frequency distribution of PRA for 123 normal subjects and 195 cases of essential hypertension aged under 59 years are demonstrated in Fig. 2 . In normal subjects, 116 persons out of $123(94 \%)$ had the values between 5 and $30 \mathrm{ng} / \mathrm{ml}$. Therefore, the normal range of resting levels of PRA was defined from 5 to $30 \mathrm{ng} /$ ml. In essential hypertension, an obvious deviation from the distribution curve of the control subjects was observed. The peak of the distribution curve in 


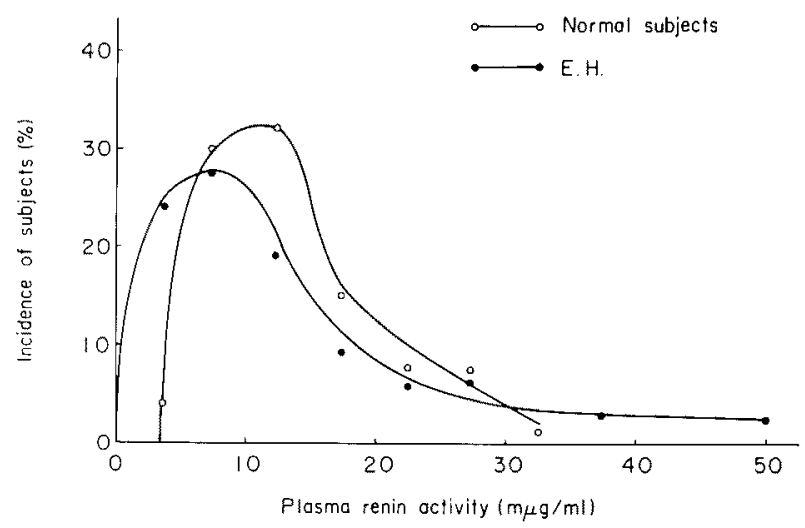

Fig. 2. Frequency distribution of resting PRA in 123 healthy persons and 195 hypertensive patients aged under 59 years.

control subjects was $12.5 \mathrm{ng} / \mathrm{ml}$, while it was $7.5 \mathrm{ng} / \mathrm{ml}$ in the hypertensive group. From these results, it may be said that the resting PRA level in essential hypertension tends to be lower than that in healthy person.

\section{Renin subgroup}

One-hundred ninety-five patients with essential hypertension aged under 59 years were classified into 3 groups according to their resting PRA values. Subnormal resting PRA level was found in 44 cases $(23 \%)$. The mean value was $2.5 \mathrm{ng} / \mathrm{ml}$ (s.E. 0.1) with a range of less than 2 to $4.9 \mathrm{ng} / \mathrm{ml}$. Normal PRA level was obtained in 127 cases $(65 \%$ ). The mean PRA value was $12.6 \mathrm{ng} / \mathrm{ml}$ (s.E. 0.59) with a range of 5 to $30 \mathrm{ng} / \mathrm{ml}$. The remaining 24 patients $(12 \%)$ had high resting PRA values in whom the mean PRA value was $57.7 \mathrm{ng} / \mathrm{ml}$ (s.E. 4.8) with a range of 31 to $100 \mathrm{ng} / \mathrm{ml}$.

Mean ages of renin subgroup were $38 \pm 13.2$ years in low, $36 \pm 12.0$ years in normal, and $34 \pm 12.7$ years in high resting PRA groups. There were no significant differences among the mean ages of three groups $(p>0.0 .5)$. Mean values of systemic arterial pressure were $174 \pm 36.2 / 106.1 \pm 16.4 \mathrm{mmHg}$ in the low PRA group, $183.2 \pm 29.8 / 108.3 \pm 16.9 \mathrm{mmHg}$ in the normal PRA group and $178.3 \pm$ $16.9 / 110.4 \pm 22.8 \mathrm{mmHg}$ in the high PRA group. Among the blood pressures of three groups, significant differences were not found either $(p>0.05)$.

\section{Incidence of low renin at different ages}

The incidences of low PRA, normal PRA, and high PRA hypertension of different ages are illustrated in Fig. 3. Twenty percent of younger patients aged under 19 years were with low PRA values. 20 to $25 \%$ of patients aged 20 to 59 years had low PRA levels. Regarding the incidence of low renin hypertension, there were no significant differences among the decades under 60 years of age $(p>0.05)$. In this age range, 60 to $70 \%$ of patients had normal PRA levels and the incidences 


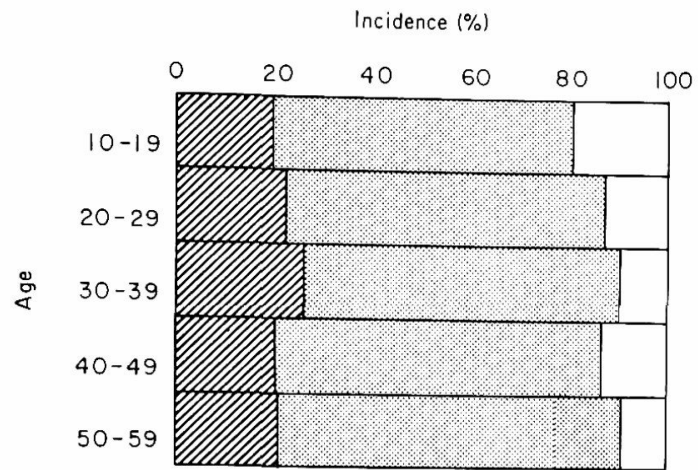

Fig. 3. Incidences of low PRA, normal PRA and high PRA hypertension at different ages. प्याया low PRA; $\square$ normal PRA; $\square$ high PRA.

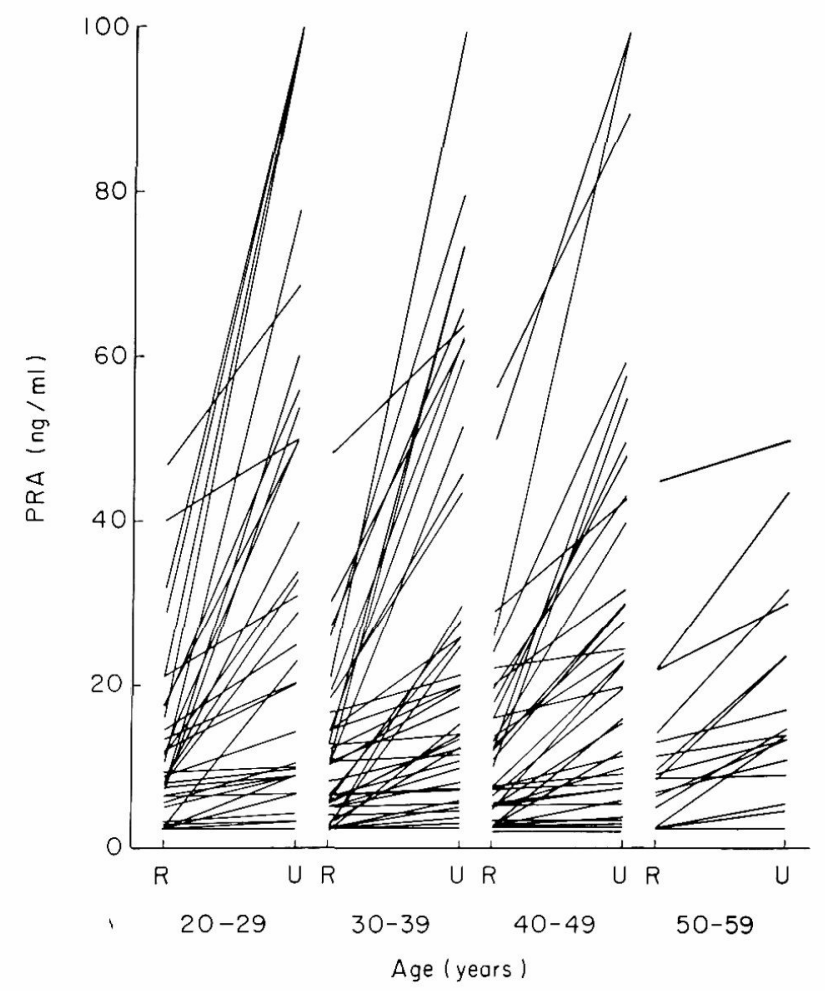

Fig. 4. Reaction of PRA to the stimulation by intravenous furosemide injection followed by upright posture in 138 hypertensive patients aged 20 to 59 years. R, Resting PRA; $\mathrm{U}, \mathrm{PRA}$ after the stimulation

were not related to the age. High PRA hypertension was found in 10 to $20 \%$ of patients aged 10 to 60 years. 


\section{Renin secretion and aging}

Provocation of renin secretion was studied in 38 healthy subjects aged from 20 to 58 years as controls. After the load of furosemide and upright posture, the peripheral vein blood PRA values were $47.9 \mathrm{ng} / \mathrm{ml}$ (s.E. 3.6) and $85 \%$ of cases had the PRA values within the range of 15 to $60 \mathrm{ng} / \mathrm{ml}$. Therefore, this range of PRA was defined normal in the ages of 20 to 59 years. The provocation test of renin secretion was done in 138 cases of essential hypertension aged from 20 to 59 years. Fig. 4 shows the response of renin secretion in hypertensive patients at different ages. After the stimulation, the mean PRA value of 39 cases aged 20 to 29 years increased from $15.1 \mathrm{ng} / \mathrm{ml}$ (s.e. 3.0) to $40.0 \mathrm{ng} / \mathrm{ml}$ (s.E. 5.1 ) 44 cases aged 30 to 39 years increased from $10.3 \mathrm{ng} / \mathrm{ml}$ (s.E. 1.4) to $27.1 \mathrm{ng} / \mathrm{ml}$ (s.E. 3.9), 39 cases aged 40 to 49 years increased from $12.9 \mathrm{ng} / \mathrm{ml}$ (s.e. 3.4 ) to $30.1 \mathrm{ng} / \mathrm{ml}$ (s.e. 4.5), and 16 cases aged 50 to 59 years increased from $11.4 \mathrm{ng} / \mathrm{ml}$ (s.e. 2.4) to $19.6 \mathrm{ng} / \mathrm{ml}$ (s.e. 3.3), respectively. Contrary to the results in the resting peripheral vein PRA levels, an apparent decrease in the renin secretion with the age was found. There was a signficant difference in the response of renin secretion between the patients aged 20 to 29 years and those aged 30 to 59 years $(0.05>p$ $>0.01$ ). All hypertensive patients were classified into 3 groups according to their responses in renin secretion. Fifty-nine patients $(42.8 \%)$ out of 138 did not respond to the stimulus, in whom the mean PRA were $4.8 \mathrm{ng} / \mathrm{ml}$ (s.E. 0.24) at rest and $8.6 \mathrm{ng} / \mathrm{ml}$ (s.E. 0.34) after the load. Normal response of renin secretion was found in 58 patients $(42.0 \%)$, in whom PRA values increased from $14.1 \mathrm{ng} / \mathrm{ml}$ (s.E. 1.3) to $33.8 \mathrm{ng} / \mathrm{ml}$ (s.E. 1.8). The remaining 21 patients $(15.2 \%$ ) showed a hyperresponse; PRA increased from $33.0 \mathrm{ng} / \mathrm{ml}$ (s.e. 5.6) to $84.2 \mathrm{ng} / \mathrm{ml}$ (s.e. 3.3). Mean ages were $38.2 \pm 10.7$ years in hyporesponders, $36.8 \pm 10.1$ years in normal responders and $31.1 \pm 8.1$ years in the hyperresponders. There was no significant difference in mean ages between the hyporesponders and the normal responders $(p>0.05)$, while it was lower in the hyperresponder than the other two groups $(p<0.01)$.

\section{Incidences of hyporesponder at different ages}

The incidences of the hyporesponders, the normal responders and the hyperresponders of renin secretion at different ages are demonstrated in Fig. 5. The hyporesponders were found in $22 \%$ of cases aged under 19 years, $33 \%$ of cases aged 20 to 29 years, $47 \%$ of cases aged 30 to 39 years, $38 \%$ of cases aged 40 to 49 years and $56 \%$ cases aged 50 to 59 years. There was positive correlationship between the incidences of hyporesponder of renin secretion and the age $(r=0.886$, $0.01<p<0.05$ ). Higher incidences of hyporesponders was obtained in older patients, and lower incidences in younger patients. In regard to the hyperresponders, the incidence was higher in younger patients than in older patients. In the patients aged 50 to 59 years, no one showed a great response to the stimulus. The normal responders were found in 40 to $50 \%$ of patients in every decade except in the advanced ages over 60 years. There was no significant difference regarding 


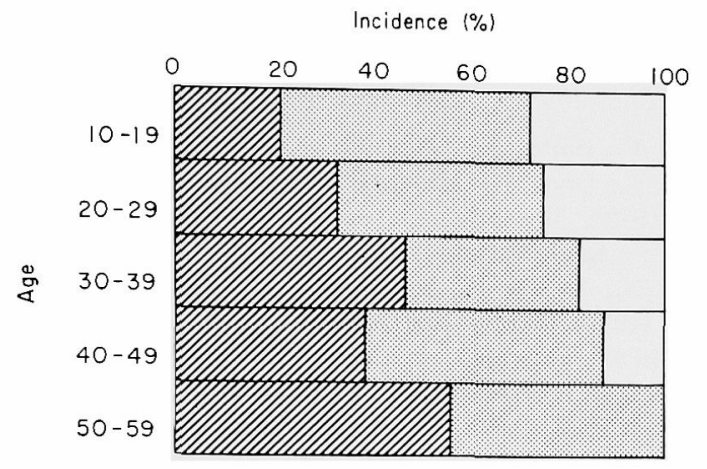

Fig. 5. Incidences of the hyporesponder, the normal responder and the hyperresponder of renin secretion at different ages. Wiella hyporesponder $\ldots$ normal responder; hyperresponder

the incidences of normal responder at the different ages $(p>0.1)$

\section{Discussion}

In the present study of hypertensive patients and the age matched control subjects, it was revealed that the incidences of low resting PRA were similar in each decade under 60 years. From this result, it seems unlikely that low renin hypertension is a stage in a long-term course of essential hypertension.

The term, low PRA hypertension, is variously used for patients with essential hypertension whose PRA is low, or renin secretion in response to the stimulus is suppressed. However, there were obvious differences between these two types of PRA patterns, because, as shown in the present study, low resting PRA hypertension was not related to the age, while the hyporesponder was apparently related to the age. There were also significant differences between the incidences of these two types of renin secretion, namely, the low PRA hypertension was found in $23 \%$ and the hyporesponder in $40 \%$ of essential hypertension.

Previously, we described that greatly increased urinary excretion of sodium by furosemide was observed in healthy persons as compared with those in essential hypertension (Memezawa et al. 1975). This result suggests that the stimulus for renin secretion through sodium and water depletion following the furosemide administration is less in essential hypertension especially in aged persons than in healthy persons, and this difference may contribute to the different incidences of hyporesponder in each decade of essential hypertension. From these reasons, it may safely be said that low PRA essential hypertension has no relation to responsiveness of renin secretion to usual stimulant of the secretion.

In addition, in our previous study (Abe et al. 1975) there was no relationship between the responsiveness of the renin secretion to furosemide injection followed by the upright posture and the hypertensive complication in the kidney and the ocular fundi, which related to only the resting PRA levels measured after overnight fasting. From these studies, it seems likely that low PRA hypertension is a 
difinite subgroup from the other groups of essential hypertension.

\section{References}

1) Abe, K., Otsuka, Y., Saito, T., Chin, B.S., Aoyagi, H., Miyazaki, S., Irokawa, N., Seino, M., Miura, Y., Ono, I., Minai, K., Kobayashi, K., Seki, K., Sato, T. and Yoshinaga, K. (1972) Measurement of plasma renin activity by angiotensin I radioimmunoassay: a modification of Haber's method. Jap. Circulat. J., 36, 741-749.

2) Abe, K., Irokawa, N., Aoyagi, H., Memezawa, H., Yasujima, M., Otsuka, Y., Saito, T. \& Yoshinaga, K. (1975) Circulating renin in essential hypertension: an evaluation of its significance in the Japanese population. Amer. Heart J., 89, 723-730.

$3)$ Brunner, H.R., Laragh, J.H., Baer, L., Newton, M.A., Goodwin, E.T., Krakoff, L.R., Bard, R.H. \& Buhler, F.R. (1972) Essential hypertension: renin and aldosterone, heart attack and stroke. New Engl. J. Med., 280, 441-449.

4) Crane, M.G., Harris, J.J. \& John V.J. (1972) Hyporeninemic hypertension. Amer. $J$. Med., 52, 457-466.

5) Ledingham, J.G.G., Bull, M.B. \& Laragh, J.H. (1967) The meaning of aldosteronism in hypertensive disease. Circulat. Res., 20, (Suppl. II), 177-186.

6) Melby, J.C., Dale, L.L. \& Silson, T.E. (1971), 18-Hydroxydeoxycorticosterone in human hypertension. Circulat. Res., 28-29 (Suppl. II), 143-153.

7) Memezawa, H., Abe, K., Irokawa, N., Aoyagi, H., Yasujima, M., Seino, M., Otsuka, Y., Saito, T., Chiba, S. \& Yoshinaga, K. (1975) Sodium balance in essential hypertension: renin subgroups and the changes of urinary sodium excretion by furosemide. Jap. J. Nephrol., 17, 63-67.

8) Padfield, P.L., Beevers, D.G., Brown, J.J., Davies, D.L., Lever, A.F., Robertson, J.I.S., Schalekamp, M.A.D. \& Tree, M. (1975) Is low-renin hypertension a stage in the development of essential hypertension or a diagnostic entity? Lancet, 1 , $548-550$.

9) Sennett, J.A., Brown, R.D., Island, D.P., Yarbro, L.R., Watson, J.T., Slaton, P.E., Hollified, J.W, \& Liddle; G.W. (1975) Evidence for a new mineralocroticoid in patients with low renin essential hypertension. Circulat. Res., 36-37, Suppl. I, 2-9.

10) Woods, J.W., Hill, C., Liddle, G.W., Stant, E.G., Michelakis, A.M. \& Brill, A.B. (1969) Effect of an adrenal inhibitor in hypertensive patients with suppressed renin. Arch. inter. Med., 123, 366-370. 